\title{
Factors influencing the post-award governance of PPP projects: A proposed framework
}

\author{
Venkata Santosh Kumar Delhi ${ }^{1 *}$ and Ashwin Mahalingam ${ }^{2}$
}

\begin{abstract}
Managing the post-award phase of a PPP project is critical with respect to realizing the project's intended benefits to society at large. The impact of institutional contexts as well as strategic action by project organizations on post-award project performance have often been studied individually. However, a comprehensive framework that combines these categories, identifies specific factors within each category, as well as outcomes relevant to the post-award phase of PPP projects is missing. This study attempts to develop such a framework through content analysis of 354 peer-reviewed journal articles. The developed framework was then refined and validated using a three round personal interview based Delphi process. In doing so, the study identifies 19 critical dimensions pertaining to institutional environments and project characteristics, and 13 different strategic mechanisms that can impact outcomes in the post-award phase of PPP projects. Further, 7 outcome dimensions - financial sustainability, adaptability, legitimacy, the extent of restructuring, sustained performance, conformance to budget and conformance to schedule - are identified and conceptualized as a seven-dimensional vector that can be taken together to assess post-award project performance. The paper concludes by discussing ways by which this framework can be used to assess and predict the outcomes of PPPs post award, and attempts to contribute to our understanding of how PPPs can be successfully designed for ease of governance across their lifecycle.
\end{abstract}

\section{Keywords}

Public-Private Partnerships, Post-Award Governance, Institutional Environments, Infrastructure Governance, Strategy

${ }^{1}$ Assistant Professor, Civil Engineering Dept., IIT Bombay, Mumbai, India - 400076, email: venkatad@iitb.ac.in (corresponding author)

${ }^{2}$ Associate Professor, Dept. of Civil Engineering, IIT Madras, Chennai, India - 600036, email: mash@iitm.ac.in 
flexibility in contracts (Ling et al. 2014) etc. From an external perspective, the institutional context of a project escalates/attenuates the severity of the manifestation of uncertainties (Scott 2012). Further, the institutional context can also enable/constrain the evolution and enactment of certain governance strategies on a PPP (Henisz et al. 2012). Such environments can aid/hinder performance of PPP projects (Algarni et al. 2007). Thus, the importance of institutional environments as well as governance strategies on post-award outcomes has been given considerable attention in the literature. Such studies often highlight the impact of one or more of these factors in the postaward phase of the project. However, these studies do not comprehensively combine these essential elements - institutional as well as strategic - to develop an understanding of successful post-award governance of PPP projects. As a result, while risks/success factors are well known, developing approaches that can lead to the successful postaward governance of PPPs that integrate institutional and strategic elements in the context of a project is lacking.

A holistic framework identifying institutional as well as strategic elements is crucial in understanding the interaction between such elements in influencing PPP projects post-award. For instance, such a framework could then be used to understand the minimum set of governance strategies that could be enacted in a given institutional environment for successful outcomes. Similarly, the moderating effect of the institutional environment on various strategic elements enacted on a project could be identified. Thus a comprehensive, integrated framework is critical to substantially informing our knowledge on managing PPPs and the absence of such a framework which identifies significant institutional as well as strategic elements related to the post-award governance of a PPP project represents a significant research gap. Our main research objective for the present study is thus to develop such a robust and comprehensive framework that identifies the significant institutional and strategic elements which influence the dynamics of project governance in the post award phase of a PPP project. 


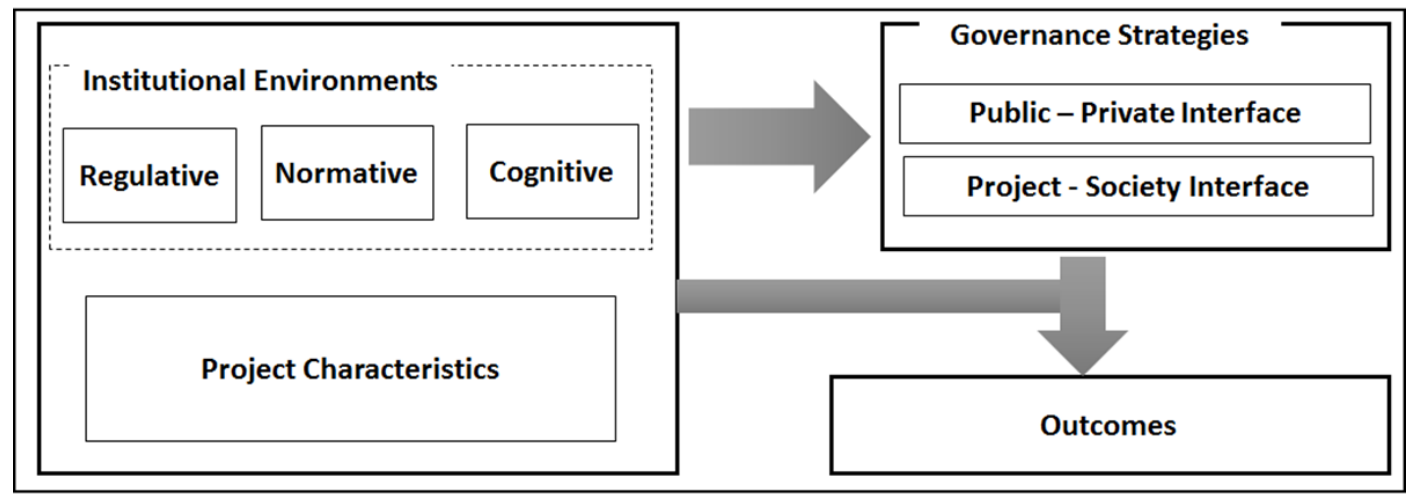

Figure 1. Initial Conceptualization of the framework

\section{Initial Conceptualization of the Framework}

To develop the framework, an initial conceptualization including both the institutional environment and the governance strategies as key elements was created in order to serve as a starting point for further elaboration and development. First, It is useful to conceptualize the institutional environment using the notion of "PPP-enabling fields" (Jooste et al. 2011). A PPP-enabling field consists of regulative, normative and cognitive elements that inhabit or make up the institutional environment within which a PPP is enacted (Scott 2008). Regulative elements are characterized by their explicit rule setting, monitoring and sanctioning processes (Powell and DiMaggio 1983). Normative elements are conceptions of the 'preferred' together with the construction of standards that are legitimate ways to pursue values which are not codified, yet are followed as appropriate (Stinchcombe 1997).Cognitivecultural elements look at shared conceptions that constitute the nature of social reality (Scott 2008). Second, for the strategic elements component, two interfaces become important for an organization executing a PPP project. The first of these interfaces is the interface between the public sector agency and the private concessionaire (referred to as the public-private interface in this article). The second interface lies between the project organization (usually a special purpose vehicle formed for the project) and the societal stakeholders, such as for instance between the users of a water supply system and the project organization delivering the service (Delhi et al. 2012), and is referred to as the project-society interface in this article. In order to manage PPP projects successfully post-award, project organizations are advised to enact strategies to govern both these interfaces through-out their lifecycle (Hodge 2004). Finally, it is anticipated that the characteristics of the PPP project itself such as the size and complexity of the project have some bearing on the management of these projects postaward (Abednego and Ogunlana 2006). Thus, the initial conceptualization of a governance framework for PPPs post-award has three major categories - Institutional Environment, Governance strategies and Project Characteristicsthat influence post-award outcomes as illustrated in Figure 1. Regulative, normative and cognitive institutional elements form the sub-categories of the institutional environment. The two interfaces identified earlier form the sub-categories of the governance strategies category.

\section{Research Methodology}

With this initial conceptualization, we take the aid of both existing literature as well as the substantive experience of practitioners to develop and validate our framework.

Content analysis was first performed on the existing literature. To this end, a total of 354 research articles on PPPs that appeared over the past 25 years were coded to identify various 
1 Table 1.Sources of the articles selected for Content Analysis

\begin{tabular}{|c|c|c|}
\hline S.no. & Journal & \# Articles \\
\hline 1 & Australian Journal of public administration & 1 \\
\hline 2 & Applied Corporate Finance & 1 \\
\hline 3 & Building Research and Information & 3 \\
\hline 4 & California Management Review & 1 \\
\hline 5 & Construction Management Economics & 52 \\
\hline 6 & Development South Africa & 1 \\
\hline 7 & Ecology and Society & 1 \\
\hline 8 & Engineering Construction and Architectural Management & 19 \\
\hline 9 & Habitat International & 15 \\
\hline 10 & IATSS Research & 2 \\
\hline 11 & International Journal of Industrial Organization & 1 \\
\hline 12 & International Journal of Project Management & 51 \\
\hline 13 & International Journal of Social Economics & 1 \\
\hline 14 & Journal of Construction Engineering and Management & 72 \\
\hline 15 & Journal of Facilities Management & 2 \\
\hline 16 & Journal of Infrastructure Systems & 16 \\
\hline 17 & Journal of International Development & 1 \\
\hline 18 & Journal of Management in Engineering & 24 \\
\hline 19 & Journal of Public Administration Research and Theory & 1 \\
\hline 20 & Journal of Urban Planning and Development & 3 \\
\hline 21 & Local Government Studies & 1 \\
\hline 22 & Oxford Journal of legal studies & 1 \\
\hline 23 & Procedia Social and Behavioural Sciences & 1 \\
\hline 24 & Public Administration & 2 \\
\hline 25 & Public Administration Review & 3 \\
\hline 26 & Public Management Review & 1 \\
\hline 27 & Public Works Management \& Policy & 5 \\
\hline 28 & Research in Transportation Economics & 29 \\
\hline 29 & The Engineering Project and Organization Journal & 2 \\
\hline 30 & The Journal of Private Equity & 1 \\
\hline 31 & Theoretical and Applied Economics & 1 \\
\hline 32 & Transport Policy & 5 \\
\hline 33 & Transport Reviews & 1 \\
\hline 34 & Transportation Research Part A: Policy and Practice & 2 \\
\hline \multirow[t]{2}{*}{35} & Transportation Research Record & 31 \\
\hline & Total & 354 \\
\hline
\end{tabular}


project characteristics and governance strategies categories that had a bearing on project outcomes, to thereby develop the framework by extending the initial conceptualization. The emergent framework was then refined and validated based on a threeround personal interview based Delphi process with experts with substantial PPP experience. Each of these steps are now discussed in detail.

\section{Development of the framework}

\section{Content Analysis}

Content analysis was performed on the existing literature to understand, define and operationalize the various sub-categories and dimensions of the framework. Articles on PPPs published between 1985 and 2014 were systematically searched. First, a search on online databases (e.g. SCOPUS) was carried out using the search strings - "Public Private Partnerships", "PPP", "Build Operate Transfer", "BOT", "Concession", "Private Finance Initiative", and "Private Participation" to identify articles that contributed to the debate on the governance of PPPs. The initial results were then filtered to include only articles dealing with management of PPPs in civil infrastructure as this was the focus of our study. After the initial filtering, the selected abstracts were read and screened to further filter out articles that did not pertain to post-award performance of PPPs. For instance, articles on PPPs that primarily dealt with the larger debates on the applicability and appropriateness of PPPs to infrastructure provision, and the legitimacy of such ventures were not considered for our study since they did not deal with project outcomes or their antecedents postaward. Next, a full study of articles that were selected after the abstract screening was carried out to ensure that the post-award performance of PPP projects was specifically dealt with in these articles. Finally, a manual search was carried out in the table of contents (for the period 1985-2014) of the journals which had the highest number of article hits in the online databases. At the conclusion of the online search followed by the manual scrutiny, a total of 356 articles from 30 different journals in total were identified as relevant to the study. The articles encompassed both positive and negative experiences/outcomes from PPPs. Table 1 lists the source of the articles selected for this study. These 30 journals deal with fields related to engineering management, publicadministration and policy, economics, accounting, social sciences etc. It should be noted that a majority of the journals are from the area of engineering management and infrastructure engineering and management. A complete list of articles is presented in Appendix A.

\section{Article Coding for content analysis}

The coding process for the identified articles was started by first importing the articles into QSRNvivo qualitative data analysis software (Richards 2002). Hierarchical descriptive coding was carried out to perform the content analysis (Jordan 2012). As the articles were read, any evidence in the articles relating to the management of the PPPs in the post-award phase were identified and coded. During this process, several initial constructs were identified. These were subsequently grouped into the categories conceptualized earlier - institutional environments (regulative, normative and cognitive sub-categories), the governance strategies across the two interfaces, the project characteristics and project outcomes. For instance, when an article pointed out that stable government policy regarding PPPs was important in supporting the management of PPP projects post-award and ensuring that governments did not intervene in the project agreement ex-post, then this evidence was coded as an instance of a construct/dimension titled "stable government policy" and was placed into the 'regulative element' sub-category of the 'institutional environment' category. Thus, as each article was read and coded, new constructs evolved pertaining to one or more of the categories/subcategories of the framework, and existing constructs were reinforced by multiple instances. In some cases, these constructs were placed directly under an existing sub-category, while in other cases, new sub-categories were evolved into which constructs were grouped. It should be noted that there could be evidence related to more than one element of the framework in the same article. Thus, in the earlier example, the same article could also have highlighted the importance of a certain governance strategy - providing equity to government organizations for instance - to be 
adopted by project organizations to effectively manage a PPP project. In such a case another instance of a construct titled 'Government Equity' would have been coded in the public-private interface sub-category of the governance strategies category, based on the article. The constructs identified were thus appropriately classified under the three major categories of the framework.

\section{Evolution of the framework during the coding process}

As a result of the coding process, a total of 28 dimensions under 8 sub-categories that fell under the 3 main categories of the framework (Institutional environments, Project characteristics and Governance strategies) were identified. Further a total of 7 different outcome indicators of relevance to the performance of PPPs were identified. Taken together, these constructs represent a systematic and grounded elaboration of the initially conceptualized framework linking post-award project outcomes on PPPs to institutional elements, project characteristics and strategies. As expected, no article contained all the elements of the framework. However, the articles alluded to some form of unexpected challenges post-award. In the present context, the number of sources citing a given construct becomes a good measure of the strength with which scholars refer to a particular construct in the context of postaward governance. Table 2 illustrates the various dimensions so generated for the framework along with the frequency of their occurrence in the literature surveyed. These dimensions will now be discussed in greater detail.

\section{Institutional Environment dimensions of the framework}

The content analysis led to the emergence of a total of 12 dimensions in the Regulative, Cognitive and Normative sub-categories of the institutional environment that were considered important for post-award management of PPP projects. Three dimensions emerged under the "Cognitive Institutions" sub-category. First, the importance of the "orientation of the state" was predominantly stressed upon by researchers. 85 out of 354 articles concluded that support from the government/state and a favourable dispensation towards PPPs is an important factor in ensuring the feasibility of the implementation and successful operation of a PPP project. Second, 32 articles indicated that an established practice of PPP delivery if present would create a favourable mind-set among project stakeholders for the implementation of a PPP project (e.g. Zhang 2009). Finally, 27 articles felt that the cognitive perceptions on a PPP would be aligned favourably through its lifecycle if some form of championship existed in favour of the project to advocate and help the project gain acceptance among various affected communities, thereby ensuring its sustainability (e.g. Caerteling et al. 2010).

Five dimensions critical to influencing PPP outcomes emerged under the Normative subcategory. First, 62 articles reported that past success stories of successful implementations of PPP projects could assert normative pressures on the public sector to take up more PPPs (e.g. Sanderson 2012). Second, 43 articles also indicated that the comfort levels for a public agency in implementing and monitoring PPPs are enhanced if some form of standard procedures or templates (e.g. Model Concession Agreements) are present(e.g. Abdul-Aziz 2012). Third, normative pressures exerted by the presence of multi-lateral agencies (e.g. the World Bank, Export Credit Agencies etc.), could encourage the enactment of sustainable strategies on PPP projects especially in the context of developing countries (39 articles). Fourth, the importance of the role of consultants in influencing the adoption, design and implementation of PPPs emerged as a dimension in this category (41 articles alluded to this concept). Finally, 29 articles referred to the normative pressures also applied by local funding and development agencies on the project stakeholders as a factor that could influence outcomes on a PPP project.

Four dimensions emerged in the Regulative category that were deemed critical to influencing the outcomes of PPPs. First, 98 articles pointed out that a stable government policy encouraging PPP projects is critical for a favourable regulative 
Table 2. Dimensions of the framework from content analysis

\begin{tabular}{|c|c|c|c|}
\hline Category & Sub-Category & Dimension & \#Articles \\
\hline \multirow{13}{*}{ 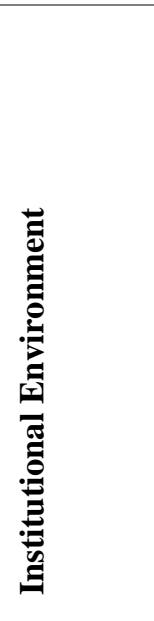 } & \multirow[t]{3}{*}{ Cognitive institutions } & Project Champion & 27 \\
\hline & & Established Practice of PPPs & 32 \\
\hline & & Orientation of the State & 85 \\
\hline & \multirow[t]{5}{*}{ Normative Institutions } & Influence of Funding Agencies & 29 \\
\hline & & Influence of Consultants & 41 \\
\hline & & Influence of Multilateral Agencies & 39 \\
\hline & & Presence of Standardized Templates & 43 \\
\hline & & Success Stories on PPPs & 62 \\
\hline & \multirow[t]{4}{*}{ Regulative institutions } & Independent Oversight & 50 \\
\hline & & Government Ordinances & 48 \\
\hline & & Legislations & 80 \\
\hline & & Government Policy & 98 \\
\hline & \multirow[t]{3}{*}{ Project-Stakeholder Interface } & Feedback from Users & 25 \\
\hline \multirow{8}{*}{ 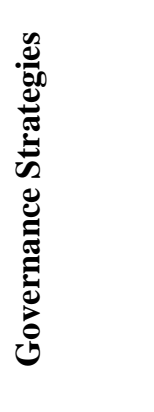 } & & Information Disclosure about the Project & 39 \\
\hline & & Fair Process of Stakeholder Involvement & 70 \\
\hline & \multirow[t]{6}{*}{ Public-Private Interface } & Government Representation on Project Board & 23 \\
\hline & & Government Equity & 23 \\
\hline & & Resolution of Conflicts & 62 \\
\hline & & Financial Buffers on Project & 72 \\
\hline & & Innovation in Project Management & 76 \\
\hline & & Flexibility in Contracts & 85 \\
\hline \multirow{7}{*}{ 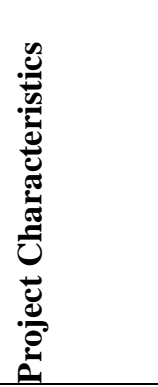 } & \multirow[t]{3}{*}{ Capability of project parties } & $\begin{array}{l}\text { Capability of the Consultants involved in the } \\
\text { project }\end{array}$ & 44 \\
\hline & & Capability of Public agency & 48 \\
\hline & & Capability of the Private concessionaire & 66 \\
\hline & \multirow[t]{4}{*}{ Project complexity } & Data Uncertainty & 20 \\
\hline & & Project Dependencies & 40 \\
\hline & & Demand Uncertainty & 62 \\
\hline & & Project Size and Incentive structure & 60 \\
\hline
\end{tabular}

environment(e.g. Fischer et al. 2006). Second, the regulative aspects are enhanced by the presence of specialized PPP specific legislations or other laws which create rule frameworks for PPP implementation ( 80 articles mention this aspect). It should be noted that such acts can encompass a number of infrastructure sectors, or specific infrastructure sectors. Further, a portion of these 80 articles (29 articles) also state that the legislations so enacted must be stable throughout the project implementation, and a large number of post award issues manifest on the project due to change of laws midway(e.g. Aziz 2007). Third, the regulative environment is enhanced by the enactment of government ordinances/orders spelling out the rights and obligations specific to a particular PPP project (48 articles). For example, a specific ordinance to provide the required legal environment was passed in Hong Kong to develop tunnels on a Build-Operate-Transfer (BOT) basis (Kumaraswamy\& Morris, 2002). Finally, researchers $(50$ articles $)$ also indicated the importance of the presence of an independent judiciary and audit agencies ("Independent 
Oversight") to provide legal comfort for a PPP project organization (e.g. Vives et al. 2010).

\section{Governance Strategies on PPP projects}

As discussed earlier, dimensions were coded into two interfaces (sub-categories of the governance strategies category) - the public-private sector interface and the project-societal interface. Across the project-societal interface, researchers (70 articles) frequently considered the adoption of a fair process involving the stakeholder community right through the project life-cycle as a key strategy. Further, studies (39 articles) also emphasized transparent sharing of information to various stakeholders from the early stages as a key strategy. Finally, it was also stressed that the project organizations should enact mechanisms to incorporate feedback from the community on the project to gain the acceptance of society (25 articles).

Across the public sector-private sector interface, a majority of studies ( 85 articles) indicated the need to incorporate some form of flexibility in contracts to deal with unforeseen eventualities in the postaward phase. Second, 72 articles also indicated that quite often PPP project organizations should bring in innovations in project management practices to bring about efficiency in service delivery. Third, 76 articles alluded to the need for creating financial buffers (e.g. government guarantees, lines of credit etc.) to help projects in times of need. Further, having a clear and unambiguous process in the resolution of conflicts, which may arise during implementation, is considered important for influencing outcomes (62 articles). Finally, researchers have highlighted strategies to bridge the usual trust deficit between the public and private sector to work together towards the intended project delivery as an important factor that affects post award outcomes of PPPs. To this end, some studies (23 articles) mention that having the government as an active participant in the partnership by contributing equity to the project could help in balancing issues across this interface. Further, 23 articles also suggest that government representation on the board of directors of the project could positively influence decision making on the project in the post award phase of a PPP project.

\section{Project characteristics critical to project governance}

The third category of the framework involves the inherent characteristics of the project which may influence/moderate project outcomes. Two significant sub-categories emerged during the coding process. These were the capability of the various players who are party to the PPP and the inherent complexity of the PPP project.

It is usually expected that the capability of the public agency (48 articles) in managing PPPs would be a significant. However, the content analysis pointed out that the capability of the private sector organization involved in the project was perhaps an even bigger concern (66 articles), since substitution of the private sector has high transaction costs. It should be noted that the capabilities here refer to the skill-sets and experience (in managing and implementing PPPs) of the public agency/private organization to the specific PPP under consideration. Further, in PPPs, the public agency is assisted by a plethora of consultants on various aspects of the project. Hence, the capability of the consultants becomes an important project characteristic or dimension (44 articles).

The complexity of PPPs in the post-award phase seems to arise from a variety of factors. 60 articles indicate that project size and incentive arrangements where the private sector takes on significant risks, increases project complexity. This dimension also deals with the size of such projects which influences the risk exposure manifold. Following this, a number of researchers (62 articles) also indicated that the inherent demand uncertainty is an important characteristic of the project which influences the performance post award. Further, project complexity increases with the number of agencies/organizations that the project has to engage and co-ordinate with. 40 articles highlight the fact that such project dependencies contribute to complexity and influence outcomes. Finally, a few studies (20 articles) indicate that complexity is also influenced 
by the quality and the uncertainty of the data available (technical data on say, soil conditions or resource data) when shaping the project pre-award. This data uncertainty usually affects the quality of the assumptions made by the project organizations which could then affect post-award outcome parameters such as final costs and durations.

At first glance, it may appear that there are some overlaps between dimensions identified in the 'Institutional environment' category and dimensions in the 'Governance strategies' or 'Project characteristics' categories. For instance, the 'orientation of the state' dimension in the institutional environment category seems related to the 'Capability of the public sector' dimension in the project characteristics category. In this context, it is critical to note that the various dimensions in the institutional environment category describe the prevailing 'rules of the game' that pervade the institutional field within which specific PPPs are executed. In contrast, dimensions within the 'Governance strategies' or 'project characteristics' categories refer to specific practices, capabilities or parameters that are present (or absent) on a particular PPP project that is under consideration. It is therefore completely possible that a supportive institutional environment for PPPs exists, but that capabilities on a particular project are low, or that governance strategies implemented are poor. The proposed framework thus allows us to capture these nuances.

\section{Outcomes relevant to post-award project governance of PPP projects}

Table 3Table 3 illustrates the seven outcomerelated dimensions that can help assess the postaward performance of PPP projects as identified from the content analysis.

First, financial sustainability of the project refers to the continuous performance of the project in providing adequate returns to the project company indicating the project's financial health (20 articles). Adaptability of the project (25 articles) refers to the adjustments both technical and financial that are enacted without amending the initial contract- for instance by changing tariffs based on contractual conditions. This outcome
Table 3.Outcome conditions for PPP projects

\begin{tabular}{lc}
\hline Outcome & \#Articles \\
\hline Financial sustainability of the project & 20 \\
Adaptability of the project & 25 \\
Legitimacy of project & 20 \\
Restructuring on projects & 29 \\
Sustained performance of project & 57 \\
Cost overrun at the end of construction & 85 \\
Time overrun at the end of construction & 90 \\
\hline
\end{tabular}

indicates the agility of the project. Restructuring of the project (29 articles) refers to the successful renegotiation of the terms of the contract itself, without disrupting the services to the end-users. This can happen due to materialization of an uncertainty which was not envisaged during the initial contract. Legitimacy of the project (20 articles) refers to the acceptance of the project within the broader stakeholder community. Sustained performance of the project (57 articles) refers to the continuous delivery of intended services to the community and users of the project. Finally, cost (85 articles) and time (90 articles) overruns at the end of construction were very common outcomes of interest in many studies. Taken together, these seven outcomes define a 'success vector' for PPPs. It should be noted that it is possible for PPPs to be partially successful by performing well in some of these dimensions and not on others. For instance, a PPP may be financially sustainable without being considered as legitimate by the user community.

\section{Refinement and Validation of framework}

The emergent framework was refined and validated by incorporating views from PPP experts in India using a Delphi process. A Delphi process essentially enables structured anonymous communication among experts to gain consensus (Linstone and Turoff 1975). The process adopted for this study is shown in Figure 2. 


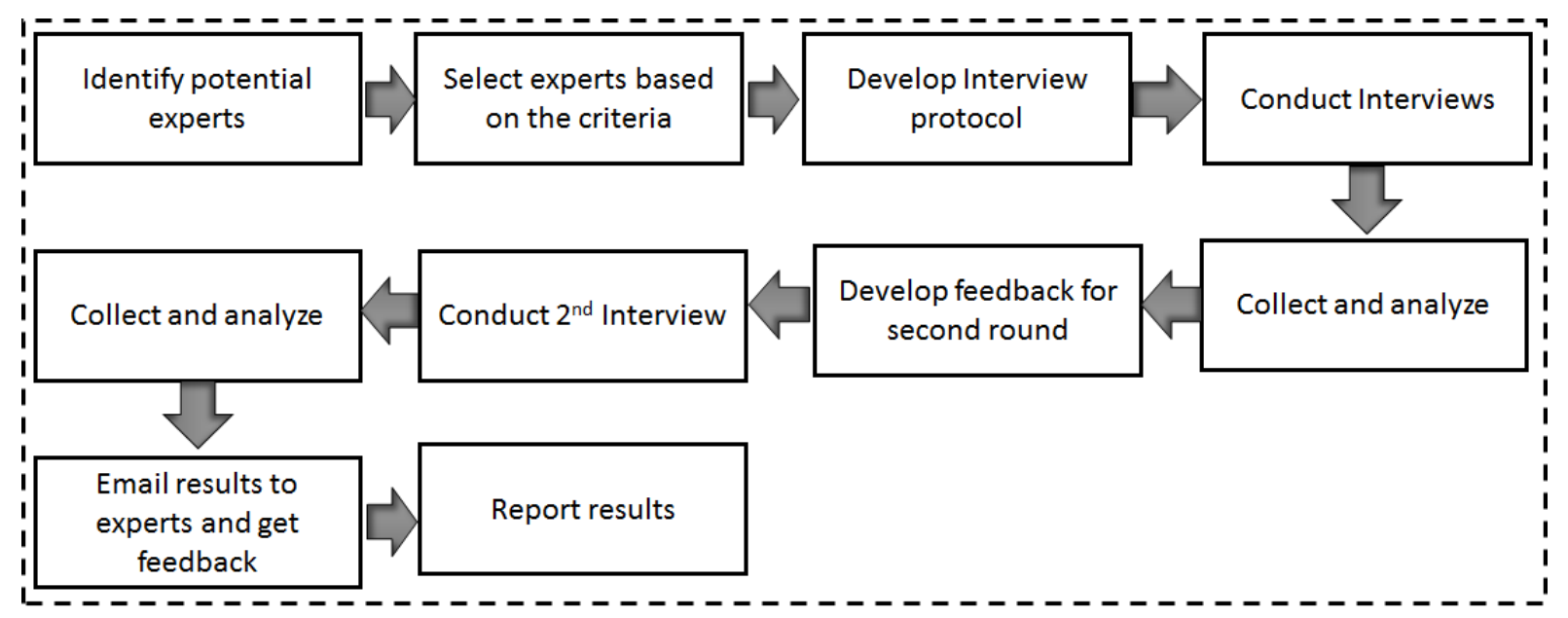

Figure 2. Method adopted for Delphi process

Initially, a scoring schema to qualify experts was framed. The scoring schema is illustrated in Table 4 and was used to identify experts in the field of PPPs. The scoring scheme weights expertise proportional to the experience/time spent by a candidate in the field of PPPs while also providing credit for time spent by a candidate to accomplish other achievements related to PPPs. Therefore, while each potential expert earns one point for each year spent in the actual practice of PPPs, they can also earn, for instance, up to 4 points for completing a $\mathrm{PhD}$ on a related topic (in most cases a full time $\mathrm{PhD}$ takes about 4 years to complete). This scoring method is consistent with recommendations in the literature on the Delphi method (e.g. see Hallowell and Gambatese 2009). A minimum score of 20 was taken as the cut-off mark to select the experts.

A preliminary list of identified potential experts was filtered using this scoring schema to form a panel of 10 experts for the study. This number falls in the accepted range of 8-12 experts suggested in the literature (Gad 2012; Hallowell and Gambatese 2009; Hyun et al. 2008). The experts were chosen from the government sector, private developers, consultants and financiers, to elicit well rounded and balanced responses. The first round consisted of semi-structured open-ended one-on-one interviews with each of the experts. The interviews were open-ended to identify dimensions not captured by content analysis and to operationalize each of the dimensions of the framework. A total of 20 hours of interviews (range: 90-150 min; average: $120 \mathrm{~min}$ per interview) were conducted during this round. During this interaction, each expert was also asked to rate the importance of each dimension in contributing towards the overall strength of the corresponding sub-category on a scale of $0-8$ ( 0 being not important and 8 being extremely important). This importance rating was used to identify the deviations of opinion among experts to generate further discussion in subsequent rounds of interviews.

The responses from the first round were collated and descriptive statistics (median, mean and standard deviation) were calculated. Following

Table 4.Scoring scheme for experts

\begin{tabular}{lr}
\hline Achievement or Experience & $\begin{array}{r}\text { Points per } \\
\text { each }\end{array}$ \\
\hline PPP experience / year of experience & 1.0 \\
Infrastructure experience / year of & 0.5 \\
experience & 1.0 \\
Member of a committee on PPPs & 3.0 \\
Faculty member at an accredited & \\
university with expertise in PPPs & 4.0 \\
Writer of a book on PPPs & 2.0 \\
Writer of a chapter on PPPs & 4.0 \\
BS & 2.0 \\
MS/MBA & 4.0 \\
Ph.D. on PPP or infrastructure related & \\
topics &
\end{tabular}


this, the interview protocols were prepared for each of the experts separately for the second round. These protocols contained responses from the concerned expert along with the most deviating responses as compared to others on every dimension. During this round, the experts were asked to comment again on the dimensions where their views differed considerably from others. Revised ratings were elicited. A total of 7 hours of interview (range: $30-60 \mathrm{~min}$; average: $45 \mathrm{~min}$ ) were conducted during this round. A broad consensus was observed at the end of the second round (the standard deviation of the responses across dimensions was less than 1.0), in consonance with the literature (de la Cruz et al. 2006). Hence, in a brief third round the consensus and deviations were emailed to the experts and their comments and ratings were again elicited. Consensus emerged at the end of this round and all the experts were informed of the final results of the study.

\section{Results from the Delphi process}

At the end of the first round, the interviews were transcribed and coded to evaluate the validity of the existing constructs and to analyse for emergent new constructs. While all of the existing dimensions found strong support from the practitioners as constructs that affected post-award performance, the Delphi process also led to the identification of a new set of governance strategies to be enacted across a third interface. This new interface called the 'public sector interface' highlights the actions/interactions within or between one or more government agencies which are involved directly or are affected by the project. The Delphi process indicated the importance of governance strategies which the public sector can adopt to manage different government agencies as well as its own internal processes to ensure the smooth functioning of PPPs. Hence, the construct'Public Sector Strategies' was added as a third subcategory/interface under the "Governance Strategies" category in the framework. Under this sub-category four dimensions emerged as key governance strategies.

The first of these strategies was to have a dedicated team of personnel to coordinate the different dependencies of the project with different government agencies to obtain various permissions and licenses required, and to coordinate with the private sector, thus acting as boundary spanners for the project. As described by one expert:

"A dedicated team which is formed
upfront and pro-actively engages in
various stages of project will be far more
effective than a team which just reacts to
situations as they arise or when you just
give coordination as an additional
responsibility to the project manager who
is already overburdened with other
things".

The second strategy was to have a rigorous project shaping process by the public sector whereby a number of consultations would be held with key stakeholders and various alternatives would be evaluated and iterated upon prior to creating the project brief - a pre-requisite for incorporation of governance strategies. The importance of this strategy was described by one expert:

"The project requires some preparatory
work before I launch into a transaction
process. Most governments think that
when you think PPP, appoint a
transaction advisor and do a bid process.
The preparatory element be it
stakeholder consultation, be it defining
the project contours, that process itself is
side stepped very often. The process
never takes place. So that rigor in the
project preparation is an extremely
crucial step in terms of the governing the
project."

The third of the strategies was to have a robust process and incentivization plan for the selection of the consultants or advisors on the project who guide and hand-hold the public sector. For instance, selecting a consultant on a 'success fee' model where final payment is contingent on project award, may lead to aggressive overly optimistic plans being prepared by consultants to ensure that projects are awarded. Given the critical role in project definition that consultants can play, methods by which capable consulting organizations are carefully chosen (through the use 
Table 5. Dimensions of the framework after Delphi process

\begin{tabular}{|c|c|c|c|}
\hline Category & Sub-Category & Dimension & \#Articles \\
\hline \multirow{13}{*}{ 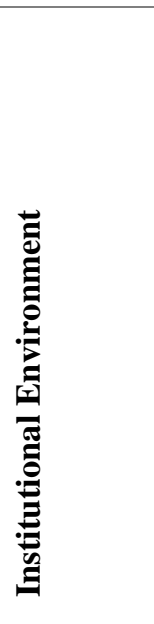 } & \multirow[t]{3}{*}{ Cognitive institutions } & Project Champion & 27 \\
\hline & & Established Practice of PPPs & 32 \\
\hline & & Orientation of the State & 85 \\
\hline & \multirow[t]{5}{*}{ Normative Institutions } & Influence of Funding Agencies & 29 \\
\hline & & Influence of Consultants & 41 \\
\hline & & Influence of Multilateral Agencies & 39 \\
\hline & & Presence of Standardized Templates & 43 \\
\hline & & Success Stories on PPPs & 62 \\
\hline & \multirow[t]{4}{*}{ Regulative institutions } & Independent Oversight & 50 \\
\hline & & Government Ordinances & 48 \\
\hline & & Legislations & 80 \\
\hline & & Government Policy & 98 \\
\hline & \multirow[t]{3}{*}{ Project-Stakeholder Interface } & Feedback from Users & 25 \\
\hline \multirow{12}{*}{ 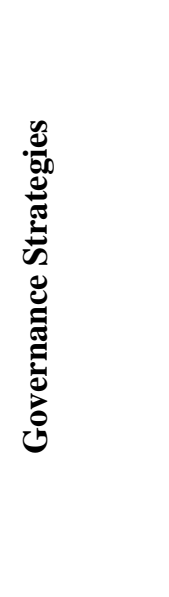 } & & Information Disclosure about the Project & 39 \\
\hline & & Fair Process of Stakeholder Involvement & 70 \\
\hline & \multirow[t]{6}{*}{ Public-Private Interface } & Government Representation on Project Board & 23 \\
\hline & & Government Equity & 23 \\
\hline & & Resolution of Conflicts & 62 \\
\hline & & Financial Buffers on Project & 76 \\
\hline & & Innovation in Project Management & 72 \\
\hline & & Flexibility in Contracts & 85 \\
\hline & \multirow[t]{4}{*}{ Public Sector Interface } & Continuity of Project Public Officers & 06 \\
\hline & & Selection of Consultants & 08 \\
\hline & & Integrators on Projects & 13 \\
\hline & & Rigor in Project Shaping & 63 \\
\hline \multirow{7}{*}{ 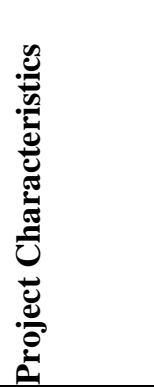 } & \multirow[t]{3}{*}{ Capability of project parties } & $\begin{array}{l}\text { Capability of the Consultants involved in the } \\
\text { project }\end{array}$ & 44 \\
\hline & & Capability of Public agency & 48 \\
\hline & & Capability of the Private concessionaire & 66 \\
\hline & \multirow[t]{4}{*}{ Project complexity } & Data Uncertainty & 20 \\
\hline & & Project Dependencies & 40 \\
\hline & & Demand Uncertainty & 62 \\
\hline & & Project Size and Incentive structure & 60 \\
\hline
\end{tabular}

of mechanisms such as pre-qualification) and incentivized to provide objective judgments on the project (through incentive mechanisms that discourage overly optimistic presentations of the project) are likely to have a bearing on project outcomes. Finally, ensuring the continuity of knowledge in the public sector either by making sure that the same project officers hold office during the life time of the project or having processes to institutionalize project knowledge, is important. As one expert quoted:

"The continuity of project officers, who are responsible for the project is crucial. There will be one fellow who would have 
The Engineering Project Organization Journal (October 2017) 7, 2

Table 6. Final ratings given by the experts in the Delphi process

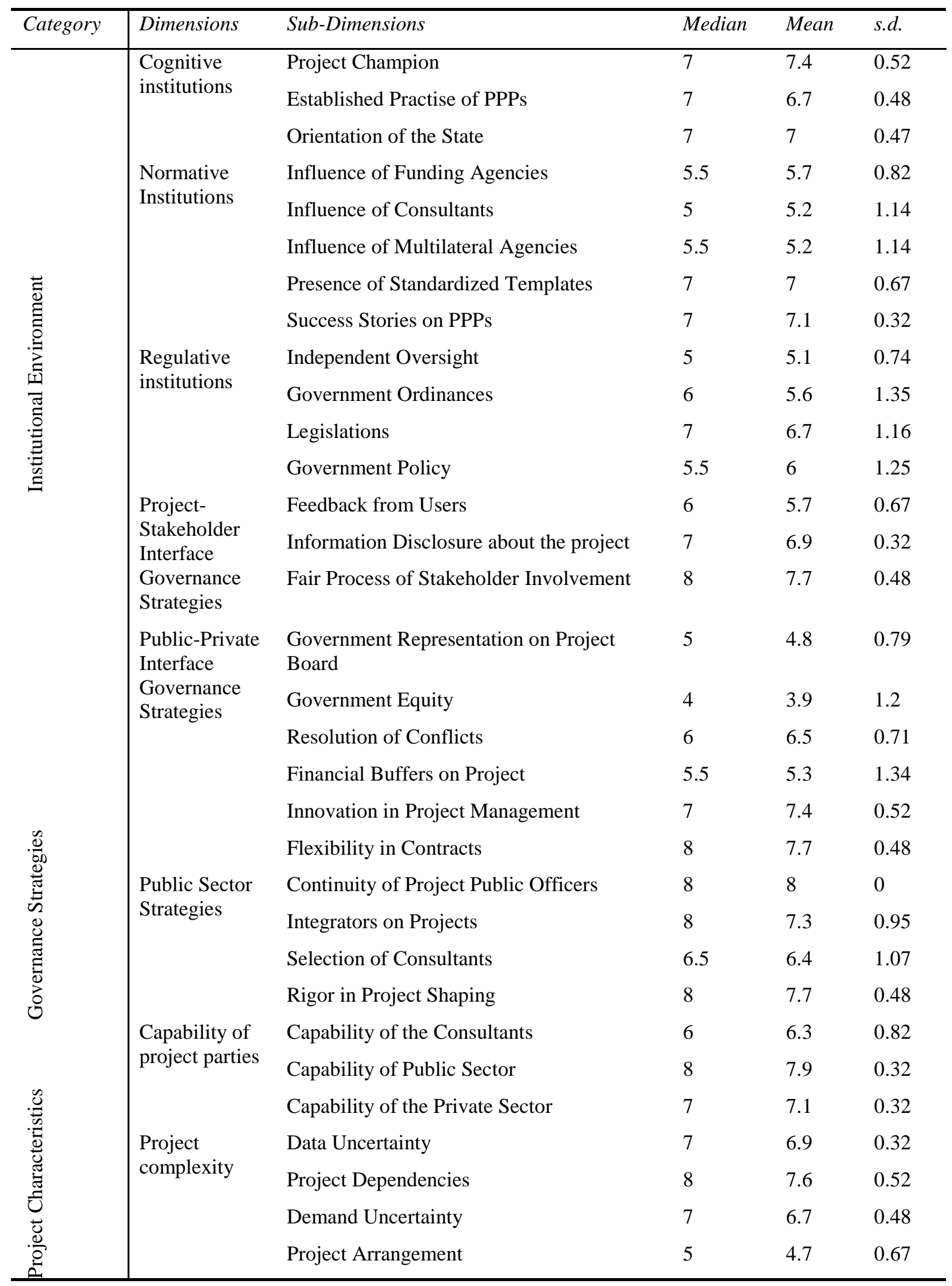


fellow who approved the bid documents. Then, there will be a third fellow who would be monitoring the project. No way will a project succeed with that approach."

Following the evolution of these new strategies under the public-sector strategies sub-category, the articles which were content analysed earlier were revisited to understand the frequency with which existing research has indicated the newly emergent strategies as important. It is found that these strategies were not usually investigated from the perspective of their impact on the post award phase. However, a few articles referred to these strategies as being important for ensuring good structuring of projects. Table 5 shows the final comprehensive set of dimensions in our framework including the number of articles citing the different public-sector strategies that emerged from the Delphi study (the four governance strategies across the public sector interface are highlighted in italics).

As expected a number of articles (63 articles) indicated that a rigorous shaping process is important to achieving good project structures. However, not many of these articles refer to the impact of such processes on the post-award phase of the project. Very few articles (13 articles) point out that there is a need to have a coordinating team to take care of various project dependencies. Ensuring continuity among public officers and having a robust selection procedure for the selection of consultants on a PPP were also referred to but not highlighted frequently ( 6 and 8 articles respectively).

Table 6 illustrates the final ratings given by the experts during the Delphi process. It can be observed from the table that all the sub-dimensions of the framework except one received a mean rating of 4 (important) or above (contribution of equity by the Government received a mean score of
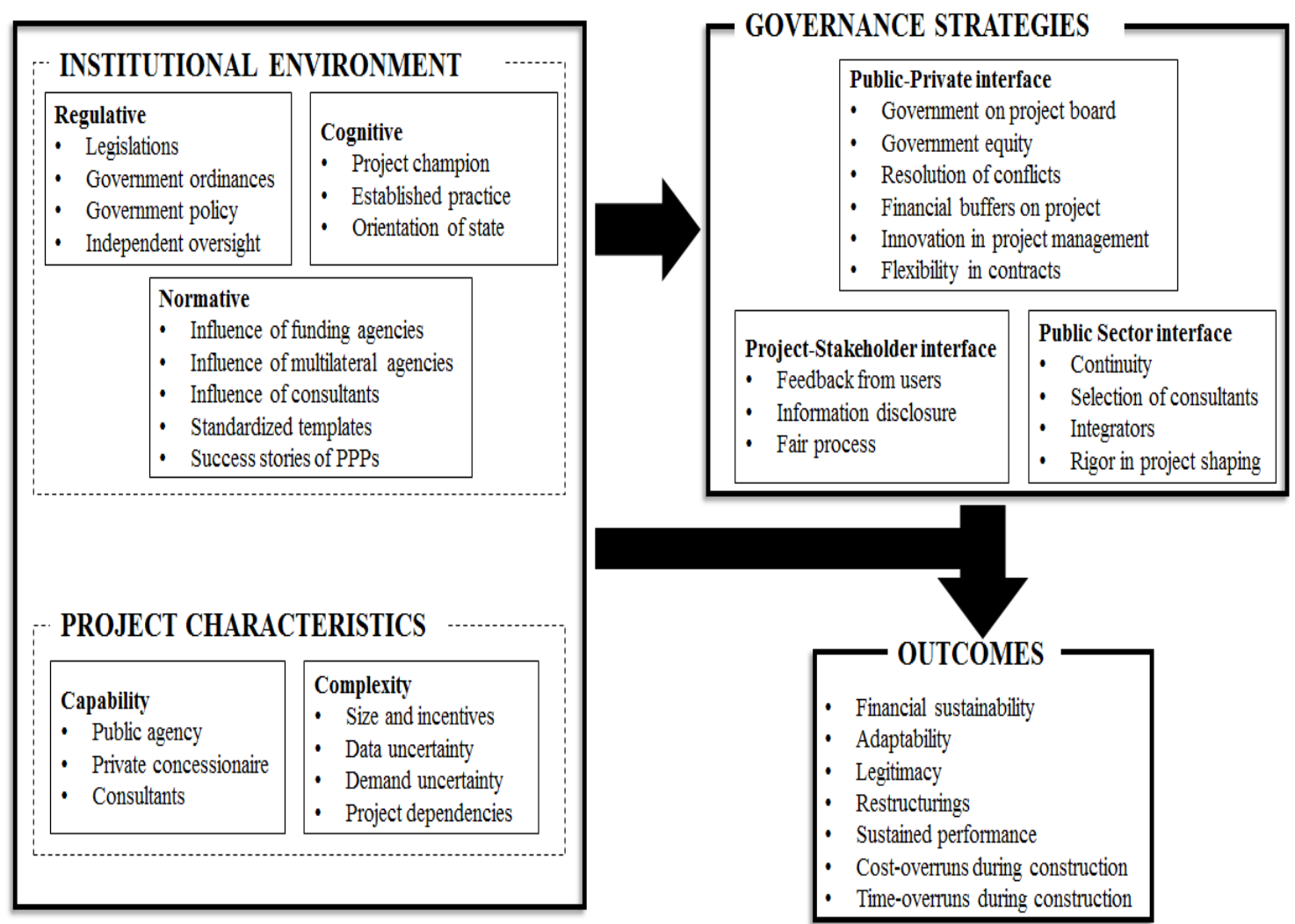

Figure 3.Final Framework after Delphi process 
3.9). This indicates that the framework captures the important dimensions that relate to the project governance of the PPP projects. It should also be noted that the perception about the relative importance of dimensions within each subcategory generally aligns with the relative frequency with which the articles in the surveyed literature have cited that dimension.

Figure 3 illustrates the final governance framework incorporating the additions through the Delphi process.

As per the aims of our study this framework integrates literature and the expertise of practitioners into a comprehensive framework that connects project structure, strategic actions and the institutional environment with outcomes on PPPs.

\section{Operationalization of the framework}

The framework was operationalized by creating a calibration schema which provides an objective basis to rate the strength of different dimensions of the framework for a PPP project on a scale of 0 to 1. Once the Delphi process was concluded, the content analysis as well as the interviews from experts were used to create this schema. By incorporating inputs from both the content analysis and the views from experts during the Delphi process, the calibration schema so developed was grounded in the extant research literature as well as substantive practical knowledge and experience from the field.

Each of the dimensions are modelled as fuzzy sets in the schema. The membership score on a dimension for a particular PPP project will define the confidence with which that project can be said to demonstrate strength in that dimension of the framework. For instance, a score of 1 on the dimension "Legislation" would mean that the PPP project was implemented in an institutional environment where strong legislation pertaining to PPPs was present.

In practice, the evidence on a project could present a range of strengths from 0 (definitely poor) to 1 (definitely strong). To relatively place the strength of a dimension as a membership function, the following fundamental, generally accepted schemes for determining membership are adopted. These schemes are usually found in studies using Qualitative Comparative Analysis (QCA) but are generalizable so as to be used in other types of analysis as well (Ragin 2008). The schemes adopted were Crisp-set (classification of 0 or 1 ), Four value membership (0-0.33-0.66-1), Five value membership (0-0.25-0.5-0.75-1) and Six value membership (0-0.2-0.4-0.6-0.8-1) (BergSchlosser et al. 2009; Jordan 2012; Ragin 2008). Based on the states exhibited by a particular fuzzy set (here a dimension of the framework), an appropriate membership scheme was used.

Using these principles or schemes and based on content analysis and expert interviews, the distinguishable states for each of the 32 dimensions and the 7 outcome dimensions were identified. Once, these states were identified, the schemes for rating using four, five and six value functions were then created to map these states to appropriate rating of the dimension. Table 7 illustrates calibration schema for one such dimension "Legislations", where five states were identified from content analysis and expert interviews. The full calibration schema developed for the 32 dimensions and 7 outcomes are presented in Tables A1 through A9 in Appendix 2.

Table 7. Sample calibration scheme for Legislation dimension

\begin{tabular}{lr}
\hline Dimension & Score \\
\hline Legislations & 1 \\
$\begin{array}{l}\text { Act was enacted before the project. } \\
\text { Supplemental Acts were enacted before the } \\
\text { project }\end{array}$ & \\
$\begin{array}{l}\text { Act was enacted before the project. } \\
\text { Supplemental Acts enacted after the project }\end{array}$ & 0.75 \\
$\begin{array}{l}\text { Acts were enacted before the project but } \\
\text { amended later on }\end{array}$ & 0.50 \\
$\begin{array}{l}\text { Act and supplemental acts were enacted after } \\
\text { the project }\end{array}$ & 0.25 \\
$\begin{array}{l}\text { No specific acts for the project. Existing } \\
\text { Acts do not support PPP }\end{array}$ & 0 \\
\hline
\end{tabular}


Using this calibration schema, the strength or weakness of various dimensions in the framework can be assessed in the context of a particular PPP project. By including data from multiple PPP projects and by employing analytical techniques such as Qualitative Comparative Analysis (QCA) or statistical analyses, pathways or combinations of factors that lead to successful project outcomes on PPPs can be identified. These combinations or pathways can then lead to the development of a series of principles for the contingent design of PPP projects under a variety of environmental and project conditions.

It should be noted here that a rigorous demonstration of this kind of theory-building using this framework is beyond the scope of this paper Delhi (2014) and Delhi and Mahalingam (n.d. forthcoming) describe the results of QCA analysis conducted on 12 case studies of PPPs coded on the basis of the framework developed here. However, to illustrate how the framework can be operationalized and applied to PPP projects, we take the case of an airport that was recently developed in India on a Build-Operate-Transfer basis. The airport project was one of the first PPPs of its kind in India and therefore normative supports in the institutional environment were low. Yet, the presence of strong regulatory institutional supports in terms of PPP legislations and an executive ordinance surrounding the PPP, as well as strong cognitive supports in the form of a dedicated project champion were observed. In addition, the project was highly complex with a number of dependencies. While strategies across the project-stakeholder interface were not observable, strategies across the other interfaces such as the use of integrators to coordinate between public departments, advanced project management techniques and equity held by the public sector in the project, were enacted. Outcome-wise, the project performed well across the financial sustainability, adaptability, sustained performance, cost and time overrun parameters. By calibrating variables using the calibration schema, this case was coded to generate values across each of the dimensions of the framework. Table 8 shows the rating of strengths of each of the dimensions on a scale of $0-1$. Once the dimensions of the framework are rated, they can be represented
Table 8. Coding of dimensions for International Airport Project

\begin{tabular}{|c|c|}
\hline Sub-Dimension & Score \\
\hline \multicolumn{2}{|l|}{ External Interface } \\
\hline Process & 0.5 \\
\hline Data & 0.25 \\
\hline Feedback & 0.5 \\
\hline \multicolumn{2}{|l|}{ Internal Interface } \\
\hline Project Management & 0.75 \\
\hline Resolution of conflicts & 0.25 \\
\hline Equity by government & 0.75 \\
\hline Composition of Project Board & 0.75 \\
\hline Flexible Contracts & 0.75 \\
\hline Financial Buffers on Projects & 0.5 \\
\hline \multicolumn{2}{|l|}{ Public Sector Interface } \\
\hline Integrators & 1 \\
\hline Consultants & 0.25 \\
\hline Rigor in shaping & 1 \\
\hline Continuity & 0.5 \\
\hline \multicolumn{2}{|l|}{ Cognitive Elements } \\
\hline History of PPPs & 0 \\
\hline Ideological Orientation & 1 \\
\hline Project Champion & 1 \\
\hline \multicolumn{2}{|l|}{ Normative Elements } \\
\hline Multilateral Agencies & 0 \\
\hline Financial Agencies & 0 \\
\hline Success Stories & 0.25 \\
\hline Standardized Procedures & 0.25 \\
\hline Presence of consultants & 0.25 \\
\hline \multicolumn{2}{|l|}{ Regulative Elements } \\
\hline Legislation & 0.75 \\
\hline Executive Order & 1 \\
\hline Government Policy & 1 \\
\hline Independent Judicial Systems & 0.5 \\
\hline \multicolumn{2}{|l|}{ Complexity } \\
\hline Project Structure & 1 \\
\hline Demand Uncertainty & 1 \\
\hline Data Uncertainty & 0.25 \\
\hline Project Dependencies & 0.99 \\
\hline \multicolumn{2}{|l|}{ Outcomes } \\
\hline Adaptability of the project & 1 \\
\hline Legitimacy of the project & 0.75 \\
\hline Successful restructuring on projects & 0.75 \\
\hline Sustained performance of the project & 1 \\
\hline Financial sustainability of the project & 1 \\
\hline Cost overrun on the project & 1 \\
\hline Time overrun on the project & 0.27 \\
\hline
\end{tabular}


graphically with appropriate formats to understand the strength of each of the dimensions on a particular project.

For example, based on the ratings so obtained by applying the calibration schema to the case study data, spider-web diagrams were generated as represented in Fig 4, Fig. 5 and Fig. 6 to illustrate the strength of the institutional environment, governance strategies and the outcomes achieved on the project in the post-award phase. From Figure 4 , it can be seen that the project had strong cognitive supports (demonstrated by a rating of 1 in these dimensions) and regulative supports but very weak normative supports (demonstrated by 0 rating in strength in normative dimensions) in the institutional environment. Similarly from Figure 5, we observed a number of strategies enacted across the internal interface of the project and the public sector interface. However, very few key strategies were enacted across the external interface of the project.

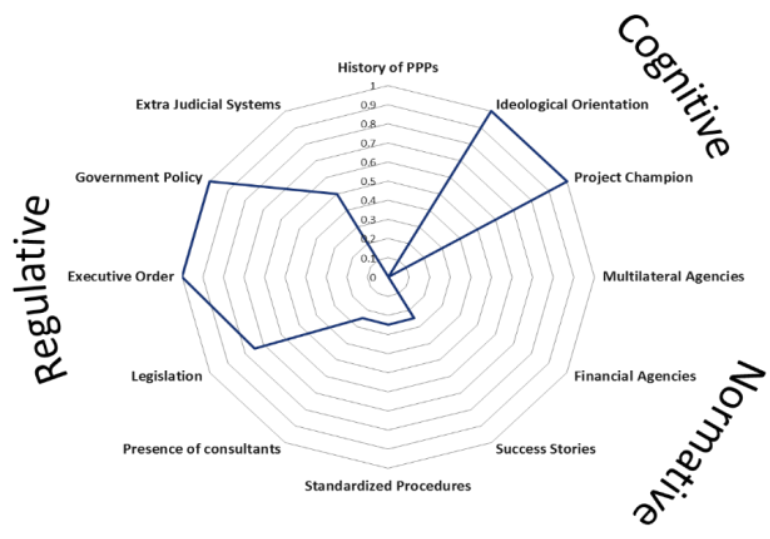

Figure 4 Institutional Environment of International Airport Project

When sufficient data across different projects demonstrates such patterns, it may be possible to propose that the absence of normative supports was compensated by the presence of cognitive supports in the institutional environment, which when combined with strategies such as the use of integrators to liaise between departments allowed the project to be completed on time and budget by overcoming coordination delays in construction. Thus such pathways to project success can be hypothesized and tested against datasets generated from other projects.

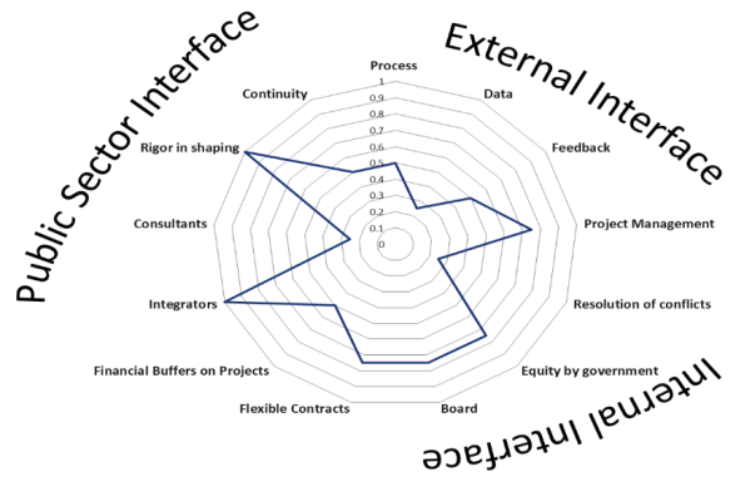

Figure 5 Strategies adopted on International Airport Project

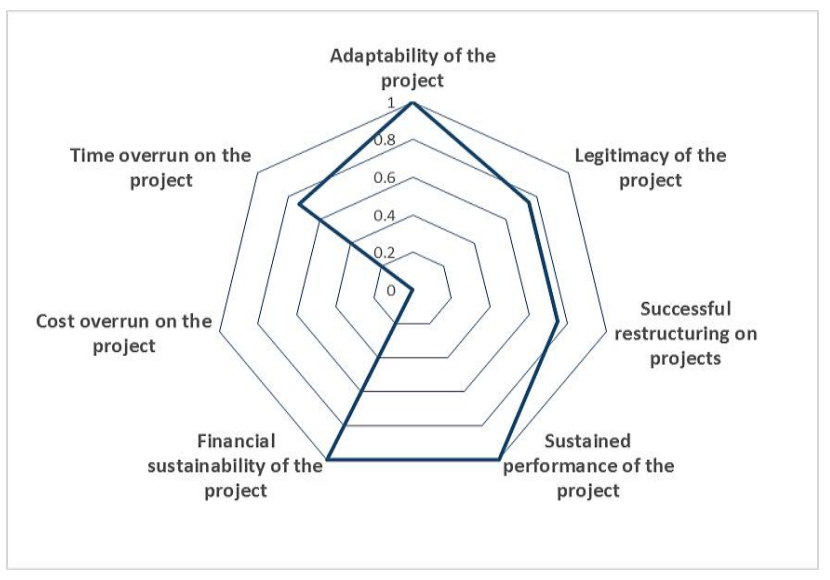

Figure 6 Outcomes on International Airport Project

\section{Discussion}

The content analysis has brought to light several salient insights from the literature. First, the success of a PPP project is multi-dimensional as far as its performance in the post-award phase is concerned. The framework identifies a seven dimensional post-award "success vector" for PPP projects. While cost and time performance are key 
to understanding the project performance up until construction, PPPs endure longer than just the construction phase and the sustained performance of the projects on finance, relational, contractual and societal fronts becomes important. These findings reinforce the literature on PPPs where the management of PPPs throughout the life-cycle is a more important determinant of outcomes as opposed to simply measuring such projects on time and cost performance in the construction phase (Bult-Spiering and Dewulf 2008). Thus it is important to evaluate the success of a PPP project across all of these dimensions through its lifecycle.

Second, strategies enacted across three different interfaces assist project organizations to manage PPP projects post-award. The strategies across the two interfaces, public-private interface and the project organization - societal interface, were frequently studied in the literature. However, the third interface which includes actions/interactions within and among the various government agencies party to/ affected by a PPP project also becomes important as PPPs progress through their life-cycle, given the interconnectedness between public sector departments in bringing these projects to fruition. Four strategies across this interface were identified in the present study and represent a contribution to the literature since this dimension has received scant attention in extant work and consequently did not form a part of our original framework. The public sector role as pointed by a few research studies becomes important to manage a PPP throughout its life-cycle (Farrugia et al. 2008; Hayllar 2010). This points to the fact that the public sector side of the project which is usually generalized as a single entity in studying PPPs should be unpacked further to understand the dynamics among and within the various agencies involved and how this affects performance and outcomes.

Third, it should be noted that a number of dimensions identified in the institutional environment may either constrain/enable the performance of PPPs in the post-award phase. The rules, normative pressures and the cultural mindsets of the project players play an important role in facilitating a conducive environment for the implementation of PPP projects. However, the strategic mechanisms which are enacted by the project organizations also play an important role in managing the projects. It is thus possible that governance strategies that infuse confidence among project stakeholders can make up for deficiencies within cognitive elements of the institutional environment. Successful PPPs can thus be enacted even when the necessary supports from the institutional environment are not available provided that governance strategies that can mask these deficiencies can be successfully enacted, as illustrated by the discussion on the Indian Airport Project above. In this case, the project was successful across certain outcome dimensions despite the lack of strong normative supports in the institutional environment. These dynamics need to be further explored to comprehensively understand how institutional environments and strategies interact/influence each other to facilitate/constrain PPP implementation.

\section{Conclusions}

The present study primarily attempts to encapsulate the extant literature and the substantive experience of experts on PPPs to systematically develop a comprehensive typology of institutional conditions and project specific strategies that can prove significant in achieving satisfactory post-award performance of PPP projects. Given the lack of such a comprehensive, combinatorial framework, the study attempts to address this gap in extant knowledge. The present study synthesized data from 354 relevant peer-reviewed research papers as well as the experiences of 10 experts and identified 19 dimensions in the institutional environment and project characteristics categories to define the environment under which a project is implemented. The study also identified 13 strategic mechanisms which the project organizations can enact to manage PPPs post-award.

Some significant insights into the post-award management of PPPs surface from this exercise. First, both researchers and practitioners acknowledge the role of both institutional elements as well as strategic mechanisms to manage PPPs better. Second, measuring the success of a PPP 
project should look beyond the cost and time performance at construction. This study defines a seven-dimensional post-award PPP success vector. Third, the study identifies a third, important interface between various public agencies that gives rise to another set of strategic mechanisms for managing post-award phase of PPP projects.

Thus, this study is an initial step in bringing together and studying the complex interrelationships between the institutional contexts, project characteristics and governing strategies in managing projects to success throughout their lifecycle. Future research should look in greater detail at the interplay between elements of the framework on PPP projects to empirically relate institutions and project specific strategies to post-award performance on PPP projects. Project case study data can be used to test linkages between variables in the framework and identify pathways that can lead to successful project outcomes. Depending on the data available, qualitative coding of cases from primary data or the literature can be undertaken using the calibration schema generated here, Qualitative Comparative Analysis (QCA) can be performed to understand pathways in mediumsized datasets and statistical analysis can be carried out for large datasets. This can then lead to the development of theory on designing PPP projects for successful outcomes contingent on institutional and project parameters that characterize the PPP. Our attempts to operationalize the framework by developing a calibration schema is a first step in this process. We illustrated the usefulness of this framework by operationalizing and applying it to a PPP project in India. Using spider-web diagrams to graphically represent the strengths of the dimensions of the framework we demonstrated how preliminary hypotheses regarding patterns for successfully managing PPPs can be obtained. In this case the presence of cognitive supports in the institutional environment combined with strategies such as the use of integrators to liaise between departments can allow projects to be completed on time and budget by overcoming coordination delays in construction. We invite other researchers to extend or modify our calibration schema, and where possible augment its current granularity while also simultaneously generating and testing propositions relating to how PPPs may be successfully governed.

From a practitioner's perspective, such pathways can be useful to project designers as they shape projects. Promoters and designers can choose specific strategies for implementation on projects based on an understanding derived through the development of this framework on which strategies are likely to positively affect project outcomes for a project, given the characteristics of the project as well as the institutional environment within which it is situated. At the very least, a check-list of potential strategies is available as a part of this framework, which practitioners can use to inform their discussions as they deliberate on the structure of the project.

In this paper, we propose a framework that contributes to our understandings of factors and ways by which they influence post-award performance of PPPs. A preliminary test would be to verify the replicability of this framework by understanding how factors in the framework can be coded based on available data from real cases or from the literature. We believe that our methodology has led to the creation of a framework that is replicable from this perspective since we have attempted to comprehensively synthesize a large number of academic articles and amalgamate this with practitioner experiences. However, as mentioned earlier, this framework needs to be operationalized further for the development of theory and insights relevant to practice. We thus invite researchers and practitioners to contribute to this field by using this framework to develop theory on the governance of PPP projects across their lifecycle.

\section{References}

Abdul-Aziz, A.-R. (2012). "Control mechanisms exercised in Malaysian housing public-private partnerships." Construction Management and Economics, 30(1), 37-55.

Abednego, M. P., and Ogunlana, S. O. (2006). "Good project governance for proper risk allocation in public--private partnerships in Indonesia." International Journal of Project Management, Elsevier, 24(7), 622-634. 
Algarni, A. M., Arditi, D., and Polat, G. (2007). "Buildoperate-transfer in infrastructure projects in the United States." Journal of Construction Engineering and Management, American Society of Civil Engineers, 133(10), 728-735.

Aziz, A. M. A. (2007). "Successful Delivery of PublicPrivate Partnerships for Infrastructure Development." Journal of Construction Engineering and Management, 133(12), 918-931.

Berg-Schlosser, D., De Meur, G., Rihoux, B., and Ragin, C. C. (2009). "Qualitative comparative analysis (QCA) as an approach." Configurational Comparative Methods. Qualitative Comparative Analysis (QCA) and Related Techniques. Los Angeles: Sage, 1-18.

Bult-Spiering, M., and Dewulf, G. (2008). "Frontmatter." Strategic issues in public-private partnerships: An international perspective, M. BultSpiering and G. Dewulf, eds., Wiley. com.

Caerteling, J. S., Halman, J. I. M., Song, M., and Dorée, A. G. (2010). "Impact of Government and Corporate Strategy on the." Journal of Construction Engineering and Management, 135(11), 1211-1221.

Cruz, C. O., and Marques, R. C. (2013). "Exogenous determinants for renegotiating public infrastructure concessions: evidence from Portugal." Journal of Construction Engineering and Management, American Society of Civil Engineers.

da Cruz, N. F., and Marques, R. C. (2012). "Delivering Local Infrastructure through PPPs: Evidence from the School Sector." Journal of Construction Engineering and Management, 138(12), 1433-1443.

Delhi, V. S. K. (2014). "Relating institutions and governance strategies to project outcomes: A study on public-private partnerships in infrastructure projects in India." Indian Institute of Technology Madras, Chennai.

Delhi, V. S. K., and Mahalingam, A. (n.d.). "Recipes relating institutions and governance strategies on a PPP projects."

Delhi, V. S. K., Mahalingam, A., and Palukuri, S. (2012). "Governance issues in BOT based PPP infrastructure projects in India." Built Environment Project and Asset Management, Emerald Group Publishing Limited, 2(2), 234-249.

Farrugia, C., Reynolds, T., and Orr, R. J. (2008). "Public-private partnership agencies: A global perspective." Collaboratory for Research on Global Projects.

Fischer, K., Jungbecker, A., and Alfen, H. W. (2006). "The emergence of PPP Task Forces and their influence on project delivery in Germany." International Journal of Project Management, 24(7), 539-547.
Gad, G. M. (2012). "Effect of culture, risk, and trust on the selection of dispute resolution methods in international construction contracts." Iowa State University.

Guasch, J. L., Laffont, J.-J., and Straub, S. (2006). "Renegotiation of concession contracts: a theoretical approach." Review of Industrial Organization, Springer, 29(1-2), 55-73.

Hallowell, M. R., and Gambatese, J. A. (2009). "Qualitative research: application of the Delphi method to CEM research." Journal of construction engineering and management, American Society of Civil Engineers, 136(1), 99-107.

Hart, O. D. (2003). "Incomplete Contracts and Public Ownership: Remarks, and an Application to PublicPrivate Partnerships." The Economic Journal, Wiley Online Library, 113(486), C69--C76.

Hayllar, M. R. (2010). "Public-private partnerships in Hong Kong: Good governance the essential missing ingredient?" Australian Journal of Public Administration, 69(SUPPL. 1).

Henisz, W. V. J., Levitt, R. E., and Scott, W. R. (2012). "Toward a unified theory of project governance: economic, sociological and psychological supports for relational contracting." Engineering Project Organization Journal, 2(1-2), 37-55.

Hodge, G. A. (2004). "The risky business of public-private partnerships." Australian Journal of Public Administration, Wiley Online Library, 63(4), 37-49.

Hyun, C., Cho, K., Koo, K., Hong, T., and Moon, H. (2008). "Effect of delivery methods on design performance in multifamily housing projects." Journal of Construction Engineering and Management, American Society of Civil Engineers, 134(7), 468-482.

Jooste, S. F., Levitt, R. E., and Scott, W. R. (2011). "Beyond 'one size fits all': how local conditions shape PPP-enabling field development." The Engineering Project Organization Journal, Taylor \& Francis, 1(1), 11-25.

Jordan, E. (2012). "Pathways to community recovery: A qualitative comparative analysis of post-disaster outcomes." University of Colorado.

Kumaraswamy, M. M., and Morris, D. A. (2002). "Build-operate-transfer-type procurement in Asian megaprojects." Journal of construction Engineering and Management, American Society of Civil Engineers, 128(2), 93-102.

de la Cruz, M. P., del Caño, A., and de la Cruz, E. (2006). "Downside risks in construction projects developed by the civil service: the case of Spain." Journal of construction engineering and management, American Society of Civil Engineers, 132(8), 844-852. 
Ling, F. Y. Y., Ong, S. Y., Ke, Y., Wang, S. S. Q., and Zou, P. X. (2014). "Drivers and barriers to adopting relational contracting practices in public projects: Comparative study of Beijing and Sydney." International Journal of Project Management, 32(2), 275-285.

Linstone, H. A., and Turoff, M. (1975). "The Delphi method: Techniques and applications." AddisonWesley Publishing Company, Advanced Book Program Boston, MA.

Lizarralde, G., Tomiyoshi, S., Bourgault, M., Malo, J., and Cardosi, G. (2013). "Understanding differences in construction project governance between developed and developing countries." Construction Management and Economics, Taylor \& Francis, 31(7), 711-730.

Marques, R. C., and Berg, S. (2011). "Risks, contracts, and private-sector participation in infrastructure." Journal of Construction Engineering and Management, American Society of Civil Engineers, 137(11), 925-932.

Martins, J., Marques, R. C., and Cruz, C. O. (2013). "Real options in infrastructure: revisiting the literature." Journal of Infrastructure Systems, American Society of Civil Engineers.

Miller, R., and Olleros, X. (2000). "Project shaping as a competitive advantage." The strategic management of large engineering projects: shaping institutions, risks, and governance.

Powell, W. W., and DiMaggio, P. J. (1983). "The iron cage revisited: Institutional isomorphism and collective rationality in organizational fields." American Sociological Review, 48(2), 147-160.

Ragin, C. C. (2008). Redesigning social inquiry: Fuzzy sets and beyond. University of Chicago Press, Chicago.

Richards, T. (2002). "An intellectual history of NUD* IST and NVivo." International Journal of Social Research Methodology, Taylor \& Francis, 5(3), 199214.
Sanderson, J. (2012). "Risk, uncertainty and governance in megaprojects: A critical discussion of alternative explanations." International Journal of Project Management, Elsevier Ltd. APM and IPMA, 30(4), 432-443.

Scott, W. R. (2008). Institutions and organizations: Ideas and interests. Sage.

Scott, W. R. (2012). "The institutional environment of global project organizations." Engineering Project Organization Journal, 2(1-2), 27-35.

Stinchcombe, A. L. (1997). "On the virtues of the old institutionalism." Annual review of sociology, 23(1), $1-18$.

Strauss, A. L., and Corbin, J. (1998). Basics of qualitative research. Sage publications Newbury Park, CA.

Verweij, S. (2015). "Achieving satisfaction when implementing PPP transportation infrastructure projects: a qualitative comparative analysis of the A15 highway DBFM project." International Journal of Project Management, 33(1), 189-200.

Vives, A., Benavides, J., and Paris, A. M. (2010). "Selecting infrastructure delivery modalities: No time for ideology or semantics." Journal of Construction Engineering and Management, American Society of Civil Engineers, 136(4), 412418.

Wettenhall, R. (2010). "Mixes and partnerships through time." International Handbook on Public-Private Partnerships, 17-42.

Zhang, X. (2009). "Win-win concession period determination methodology." Journal of Construction Engineering and Management, 135(6), 550-558.

Zou, W., Kumaraswamy, M. M., Chung, J., and Wong, J. M. W. (2013). "Identifying the critical success factors for relationship management in PPP projects." International Journal of Project Management, Elsevier. 